\title{
An Application of GIS in the Consolidation Grouting of Rock Masses through Grouting Intensity Number (GIN)
}

\author{
Faisal Usmann ${ }^{1,2,3}{ }^{*}$, Noorzada Afridi ${ }^{3,4}$, Muhammad Safiullah ${ }^{1,3}$, Tufail Ahmad ${ }^{3,4}$, Shahbaz Rafiq ${ }^{1,2}$ \\ ${ }^{1}$ Institute of Geology, University of the Punjab, Lahore, Pakistan \\ ${ }^{2}$ College of Earth \& Environmental Sciences, University of the Punjab, Lahore, Pakistan \\ ${ }^{3}$ ACE (Associated Consulting Engineers) Pvt. Ltd., Lahore, Pakistan \\ ${ }^{4}$ University of Peshawar, Peshawar, Pakistan \\ Email: ^faisal.usman@live.com
}

How to cite this paper: Usman, F., Afridi, N., Safiullah, M., Ahmad, T. and Rafiq, S. (2017) An Application of GIS in the Consolidation Grouting of Rock Masses through Grouting Intensity Number (GIN). Open Access Library Journal, 4: e3548. https://doi.org/10.4236/oalib.1103548

Received: March 21, 2017

Accepted: April 25, 2017

Published: April 28, 2017

Copyright $\odot 2017$ by authors and Open Access Library Inc.

This work is licensed under the Creative Commons Attribution International License (CC BY 4.0).

http://creativecommons.org/licenses/by/4.0/

\begin{abstract}
The grouting of foundation rock is a critical constructional technique for most of the mega projects across the world. Grouting operations come up with the challenges of pre-planning, visualization, presentation of data, quantity control, cost effectiveness and budget management. Unless properly managed, the above factors can contribute to project complexity and cost overruns. This paper deals with the application of innovative Arc Geographical Information System (ArcGIS) to effectively present the GIN (Grouting Intensity Number) data and its interpretation. The case study is being carried out on Tarbela $4^{\text {th }}$ Extension Hydropower Project during the foundation grouting of Omega Thrust Block for Penstock area. Data taken from the grouting record are analyzed and presented through GIS. By assigning the locations (i.e., coordinates or project station number) and boreholes plan; the details for each primary, secondary and tertiary boreholes are displayed through GIS. The final data metrics retrieved from the grouting station comprises of borehole grouting logs, total grout takes, grouting stages suspended, etc. The GIN grouting report obtained from the GIS user interface delineates information on 1) Grout consumption per primary versus secondary holes; 2) Showing areas of high grout takes; where secondary, tertiary and quaternary boreholes are required; 3) The grouting stages remained unsuccessful. The final interpretation of GIS data is used to avoid unnecessary secondary, tertiary and quaternary holes executions which lead to the completion of the project within the given time frame and allocated resources.
\end{abstract}

\section{Subject Areas}

Geology 


\section{Keywords}

GIN, Consolidation Grouting, Rock Masses, Grouting, GIS, Grouting Intensity Number, Dams \& Hydropower

\section{Introduction}

A civil structure within or above the surface requires a firm and homogenous foundation for its optimal post-constructional operations with ground treatment [1]. Weak, unconsolidated and un-grouted foundations are always susceptible to deformation with the consequence of structural failure [2]. Mechanical and hydraulic characteristics of foundation ground can be improved by injecting grout [3]. Grout is a liquefied concrete, comprising of an admixture of water, cement and some additives (Bentonite, Sikaman, slag, Interaplast-Z). This admixture is used to fill up open voids, joints (transverse and longitudinal), shear zones, faults, bedding planes cavities and cracks in the foundation rocks through injecting grout [4].

The current paper is primarily focused on the utility of the "Grouting Intensity Number" (GIN) introduced by Lombardi and Deere [5] and its tracking, visualizing and reporting through a GIS application. This method involves $\boldsymbol{P}_{\max }$ (maximum pressure in bars), $V_{\max }$ (Maximum volume in $1 / \mathrm{m}$ ) and GIN Value (the product of maximum pressure in bars and injected volume in $1 / \mathrm{m}$ ) i.e. $\mathrm{GIN}=\mathrm{PV}[6]$.

Figure 1 is showing the GIN parameters that are defined by $P$-max and $V$-max and the product of both. The GIN parameters are established by the introduction of a trial grout exercise based on the mechanical characteristics of site foundation rocks [7]. This method is remarkably effective not only to acquire the best results but equally feasible to enhance the lifetime durability of the project [8].

\section{Description}

Grout is injected into the foundation rocks of Omega Thrust Block Penstock Area to reduce water ingress by filling all open spaces due to the presence of discontinuities in the foundation rock mass. Once the primary boreholes are

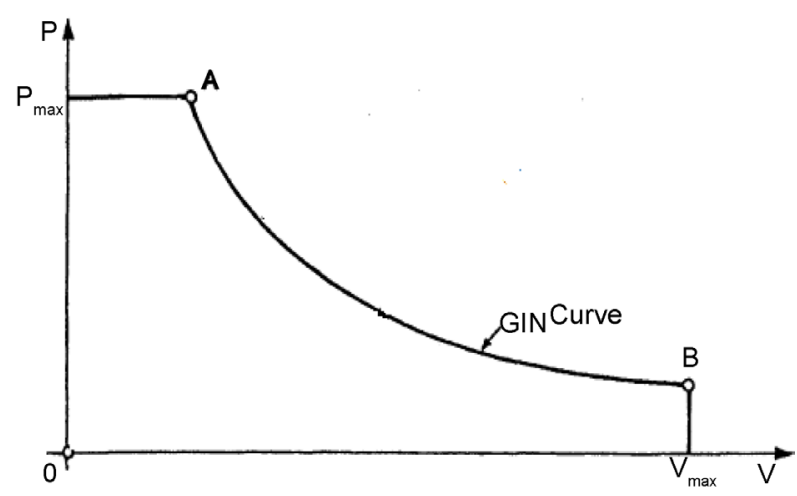

Figure 1. GIN Graph showing $P_{\max }$ and $V_{\max }$. 
completed, then the grout data is visualized through GIS. This GIS data helps to track the total grout take within each primary borehole and to identify the regions with high takes through graphical representation. The tracking of high take areas helps to decide further secondary, tertiary and quaternary boreholes location and quantity. It is evident that the GIS application has made it easy for site personals to decide the secondary boreholes in order to confine the region with regards of takes to make foundation sounder. The graphical representation by way of innovative GIS application enables to make a comparison between the grout takes of primary VS secondary boreholes and so on. This comparison helps to delineate the total grout takes and the effectiveness for the stabilization of the foundation.

The traditional field logs delay the process of getting grouting data into an electronic format. A Geographic Information System (GIS) is used to display grouting data collected. The GIS platform further extends the data analysis options for geotechnical studies. In the GIS environment querying of the data can be performed to visualize data variations across the project area. For example, top of rock bed, total grout take, borehole leakage can be displayed with a color range to give a better view of the data. GIS is a great project management tool to help with the planning phase for locating the boreholes. Once the grouting data is collected and added to the GIS, detailed maps can be produced to display project status and provide an instrument for the review of the data between offices, governmental agencies, and by the Client.

\section{Geological Setting}

Figure 2 is showing the area under current investigation that lies in the lesser Himalaya comprising the south-western part of lower Hazara. From the perspective of regional tectonics, the area structurally lies in the Himalayan Fold and Thrust Belt [9]. The Himalayan Fold and Thrust Belt extend from the Main Mantle Thrust (MMT) in the north to the Salt Range in the south [10]. On a regional scale, the major faulting system starting from North to South includes; the Main Karakoram Thrust (MKT), Kohistan Fault, Main Mental Thrust (MMT), Panjal-Khairabad fault and Main boundary Thurst (MBT). The general trend of these faults is predominantly east-west with a change in trend at the syntaxial bends [11].

Locally the Darband Fault is the most dominant left lateral strike slip fault running N-E parallel to the Indus River. This major fault is running beneath the main Tarbela Dam, forming a $214 \mathrm{~m}$ vertical escarpment in the dam foundation [12]. This fault separates the Salkhala and Tanawal formations from the Abbottabad formation on the west bank of the Indus River. The attitude of the bedding of other minor faults within the area strikes more easterly compared to the main Darban Fault [13].

The project area occupies by the Precambrian Salkhala and Tanawal formations. The Salkhala formation is Meta-sedimentary rock unit which represents the marine environment of deposition [14]. The Pre-Cambrian Salkhala formation consists of different varieties of schist, mainly are Graphitic schist, 


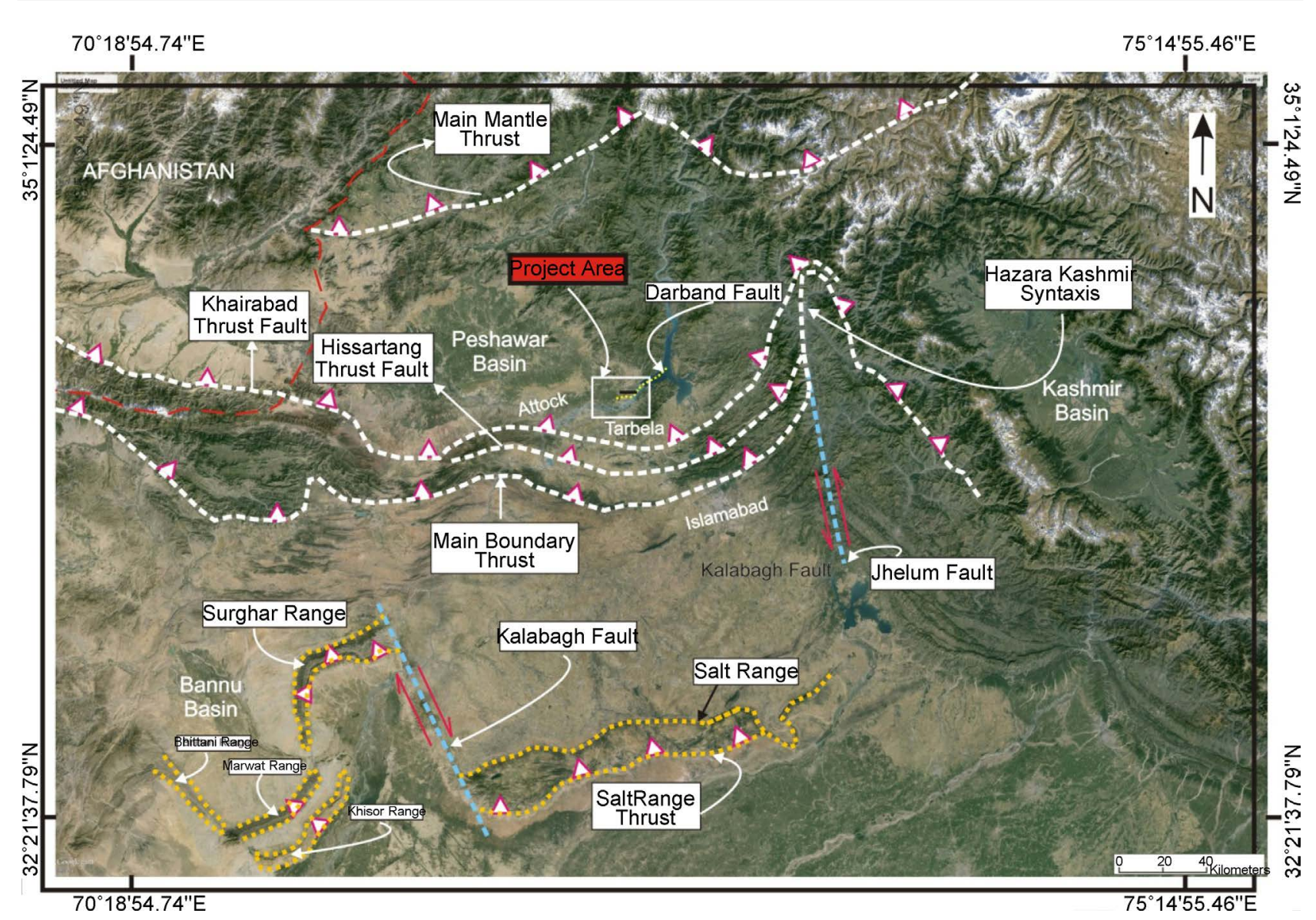

Figure 2. Regional tectonic map of the study area showing structures (after Agher, 2015).

quartz-mica schist, phyllite, crystalline limestone and quartzite [15]. The schist represents perfect foliation, micro folding and boudinage features at outcrop level. The Pre-Cambrian Salkhala formation has been intruded by a series basic to feldspathic intrusion [16]. The series of emplacement consist of gabbroic via dolerite to amphibolites albite carbonate rocks [17]. The units vary from chloritic to graphitic schist via carbonaceous schists with beds and patches of quartzite and limestone. These rock mass units are fresh to slightly weathered, fine to medium-grained, moderately to highly foliated, moderately jointed, weak to moderately strong and strong at places, imperfectly interlocked, moderately fractured, calcite and quartz veins aligned parallel to schistosity planes and pyrite inclusion observed at places [18].

\section{Methodology \& Collection of Data}

Grout holes are drilled through rotary pneumatic percussion using air as a flushing medium Grout holes are drilled through rotary pneumatic percussion using air as a flushing medium. The straight rotary drilling method is used for the drilling of boreholes. The primary holes are drilled and grouted initially. The secondary and tertiary boreholes are planned on the basis of grout take results and their assessment through GIS. These holes are kept at certain distances from each other. In this case, primary grout holes are spaced $4 \mathrm{~m}$ apart, and the sec- 
ondary borehole is in between the two primary holes with $2 \mathrm{~m}$ spacing. The tertiary boreholes are placed after analyzing the volume takes of grout in the secondary boreholes. Similarly, the quaternary boreholes are assigned by considering the grout take in tertiary boreholes. All the boreholes are drilled to the required depth of $12 \mathrm{~m}$.

The boreholes are washed using clean water after the drilling is completed. The cleaning of the borehole from debris and fines is necessary to avoid obstacles in grout injection as these particles can trap within the joints and fissures. Grouting consists of a system of networks comprising pumps, delivery pipes, agitation tanks and a computer controlled intelligent recorder. Grouting is initiated with an insertion of inflatable pneumatic packer into the borehole and tightening of the corresponding stage that needs to be grouted. Backflow of the slurry is prevented with packer and grout slurry penetrates within the boreholes into the fractures and joints at a certain pressure. The $12 \mathrm{~m}$ boreholes are grouted in two stages (002) bottom stage and (001) top stage and their grout takes are analyzed with the help of ArcGIS application.

The proposed plan for grouting of Omega Thrust Block comprises 27 Nos of Primary and 68 Nos of secondary boreholes. These boreholes need to be drilled and grouted as per set GIN grouting standards to strengthen the foundation rock. The 27 No of Primary boreholes are drilled, and their corresponding takes are analyzed with the help of Arc GIS cluster map. The cluster map obtained is helpful to identify the areas with significantly high takes. The cluster map enables to make an appropriate decision regarding the location of secondary boreholes to be executed regardless of the initial proposed plan which comprised 68 Nos of secondary boreholes. Once the grout takes of primary boreholes and associated cluster map is analyzed; the secondary boreholes are given adjacent to these high grout take areas. This step is necessary to confine the subsurface in terms of takes and to form a monolithic foundation requires for overlying civil structure. The analysis of cluster maps through ArcGIS outlines information regarding the proposed plan and grout takes. Areas with substantial takes are marked on the map.

Figure 3 is delineating the reduction in Drilling \& Grouting. The final results obtained are comprehensive as out of 68 No of secondary boreholes only 34 No of boreholes are drilled and grouted. The cluster map generated by the ArcGIS can be used to perform grout operations in the given timeframe. The grouting of 34 Nos of boreholes out of the proposed 68 Nos, indicates 50\% decrease in drilling and grouting operations which indirectly saved time and cost overruns.

\section{The GIS Results}

Figure 4 is showing the as-built grouting plan for primary and secondary boreholes. The recorded grout takes for each of the primary boreholes are analyzed and monitored using Arc GIS 10.1 software. The total grout take per each primary borehole are entered into the GIS table, and a polygon is created for the whole project. The shape file was created containing the survey coordinates of 


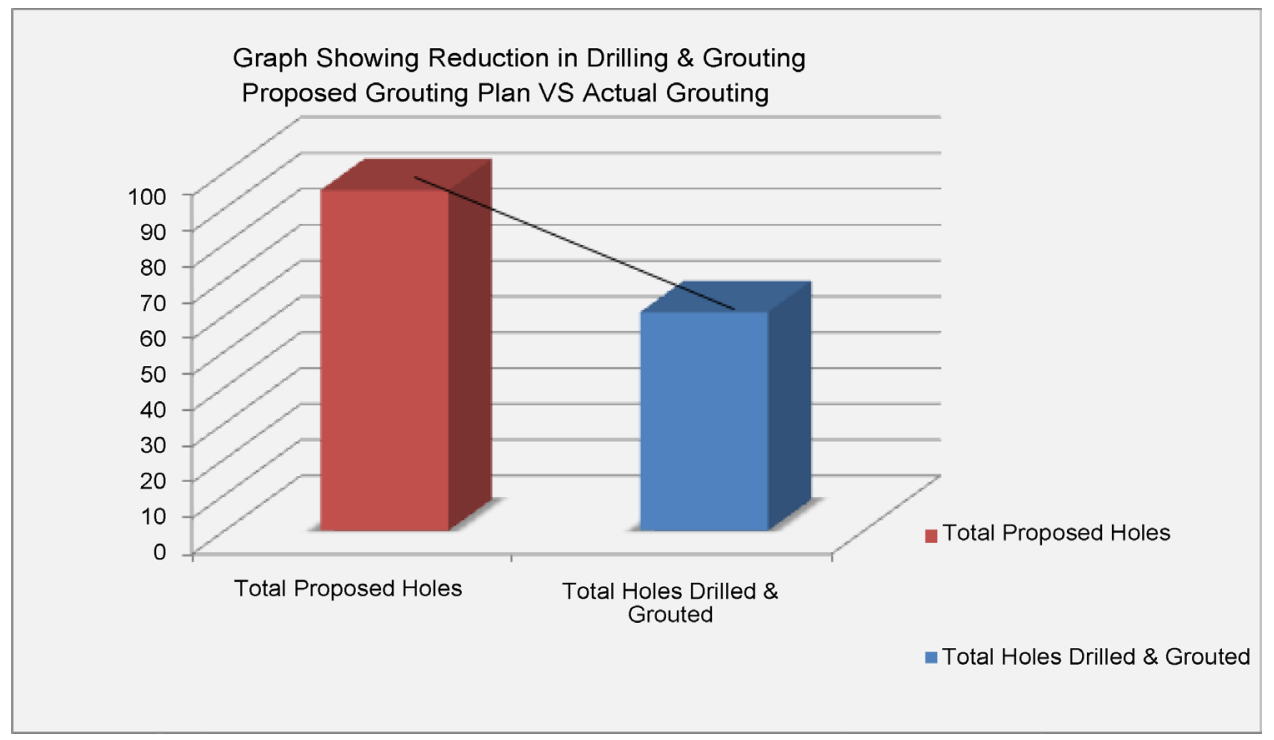

Figure 3. Graph showing reduction in drilling \& grouting.

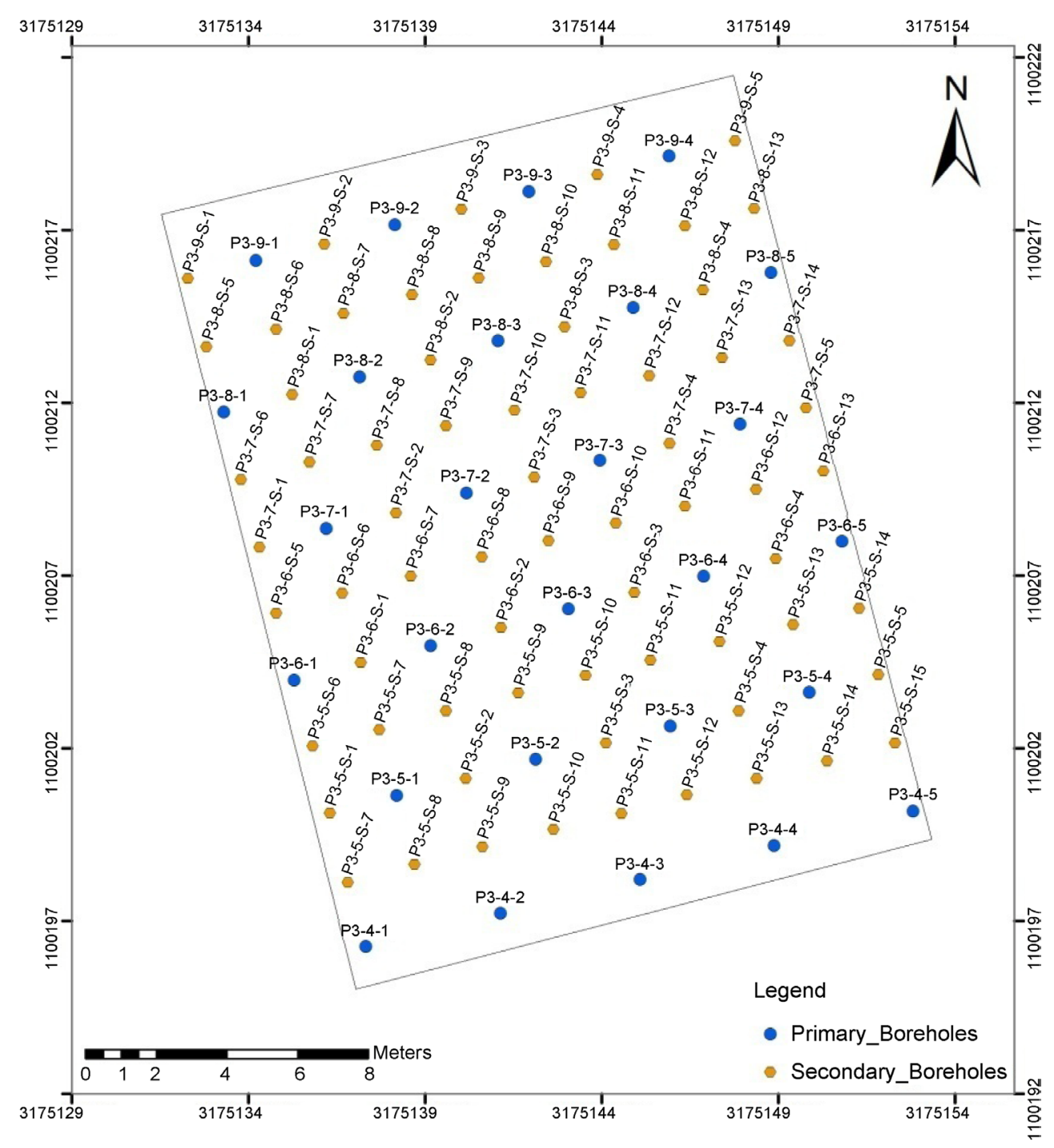

Figure 4. As built primary \& secondary boreholes location map. 
each borehole with equal spacing marked. The table was created to track the total grout take in each primary borehole which is shown in GIS by giving it range according to the GIN parameters set within the fields.

Figure 5 is depicting the total grout take in each primary borehole are analyzed, and the color ranges are given to the boreholes starting from less to high takes. The final map showed the boreholes with high takes. This data is further analyzed by the GIS software by making its cluster map, which marked the regions of high and less grout takes.

Figure 6 is pointing out the final cluster map indicating areas of high and less grout takes. The final cluster map of primary boreholes according to their grout takes is helpful to identify the areas of foundation rock masses, which are weak and prone to high grout takes. After identifying these prone areas, the location of secondary boreholes is decided to confine the area without drilling the unnecessary secondary boreholes to the regions where there is less grout takes.

Figure 7 is revealing information pertaining to the secondary borehole locations that are based on color distribution. After grouting the secondary boreholes, data is incorporated into the GIS application to identify the boreholes with High, Medium and Low takes. A range is given, and the colors are assigned
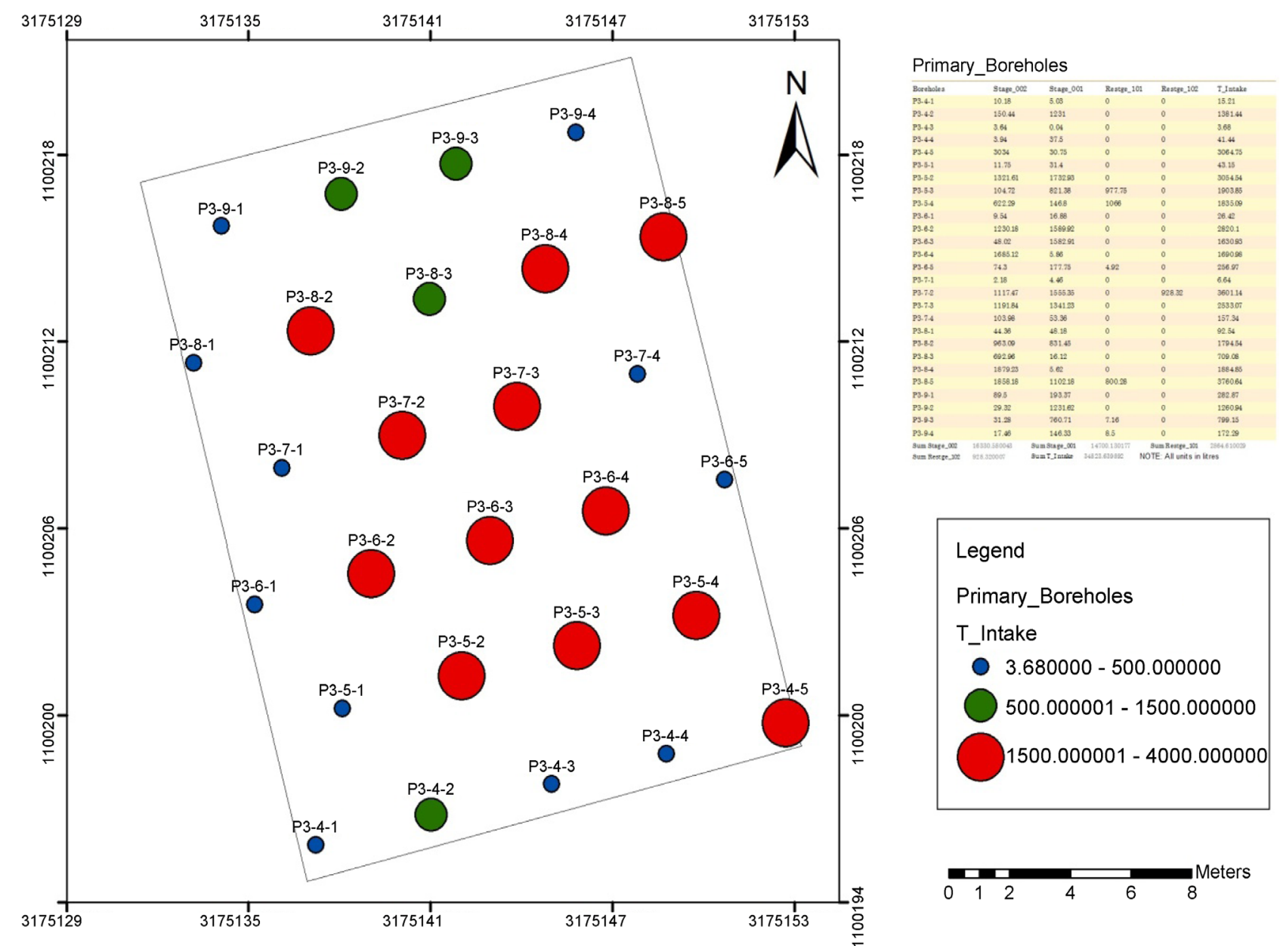

Figure 5. Primary boreholes location map (take based on color distribution of high, medium, and low). 

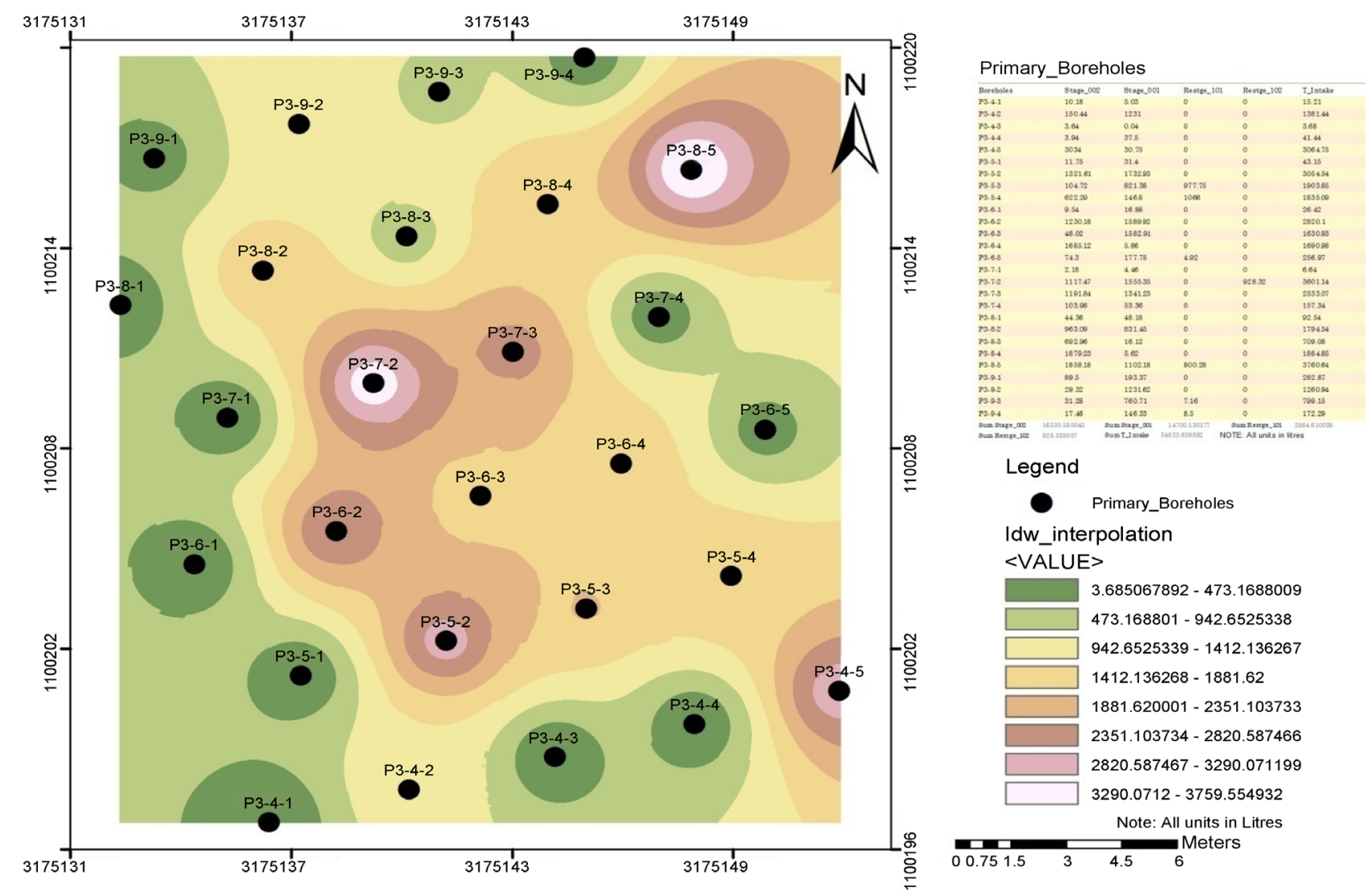

Figure 6. Cluster map showing areas of high \& less grout takes.
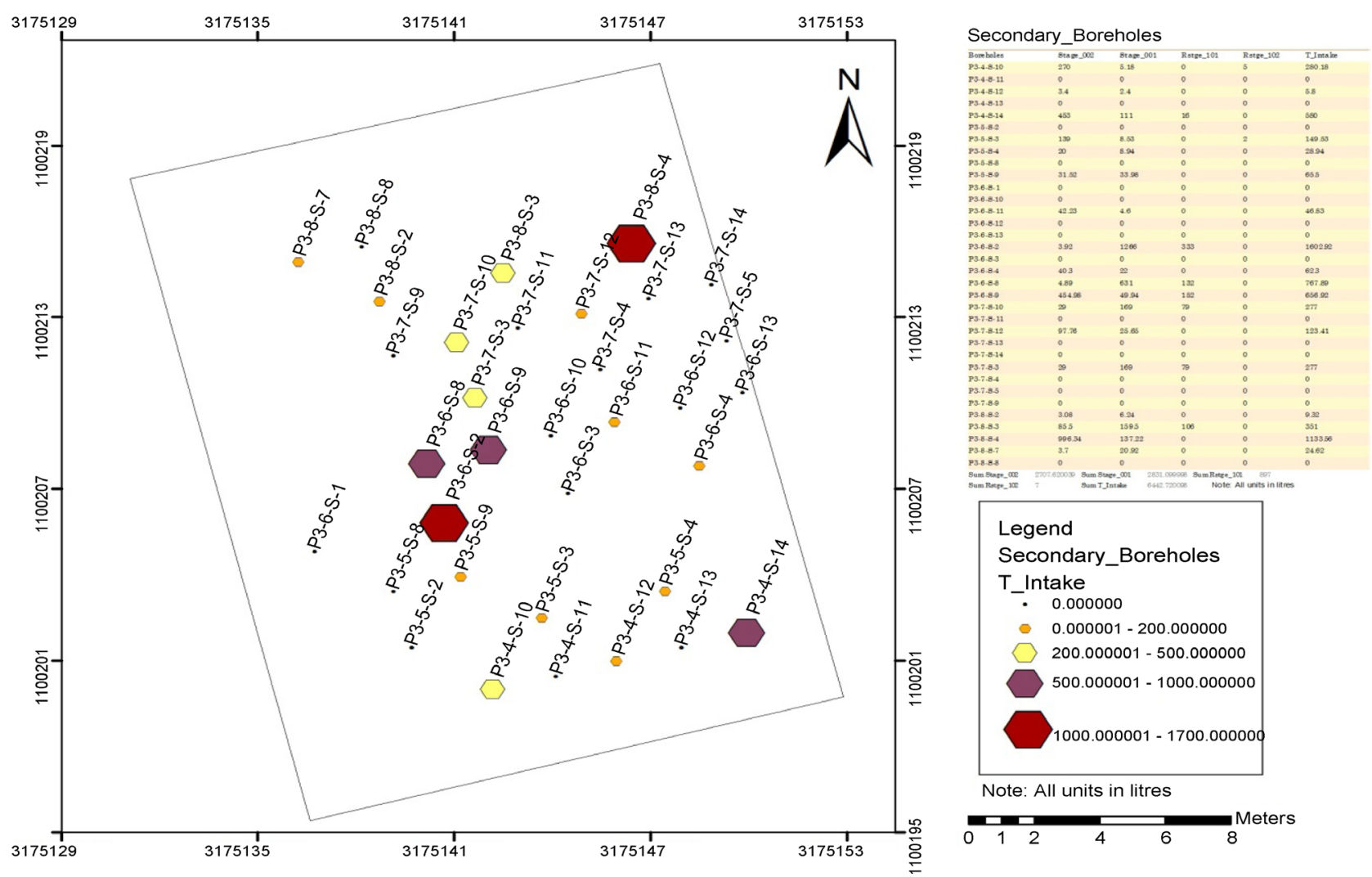

Figure 7. Secondary borehole location map (take is based on color distribution of high, medium, and low). 
to the boreholes according to their grout consumption. The final map helped to identify the boreholes with High grout takes. The cluster maps of both primary and secondary boreholes are compared to analyze to check the grouting efficiency. The final results obtained are impressing as the cluster obtained from secondary boreholes is marking only few regions with high takes and rest of the areas are grouted successfully.

It is always important to make foundation stable without leaving behind any unstable area. Keeping in view this fact Figure 8 is showing the locations of tertiary boreholes that are decided after viewing the cluster map of secondary boreholes takes. The tertiary boreholes are given adjacent to the weak areas that are prone to high grout takes. The final tertiary borehole grout takes values are incorporated within the ArcGIS by assigning the values and colors to the boreholes according to their takes.

The cluster map in Figure 9 is generated using ArcGIS to analyze the efficacy of the grouting. The results obtained were satisfactory as shown in Figure 10 as there are no further areas reported with high take and all the areas are grouted successfully without drilling unnecessary boreholes and delaying the project.

\section{Conclusion}

After evaluating the GIN grouting data of all primary, secondary and tertiary
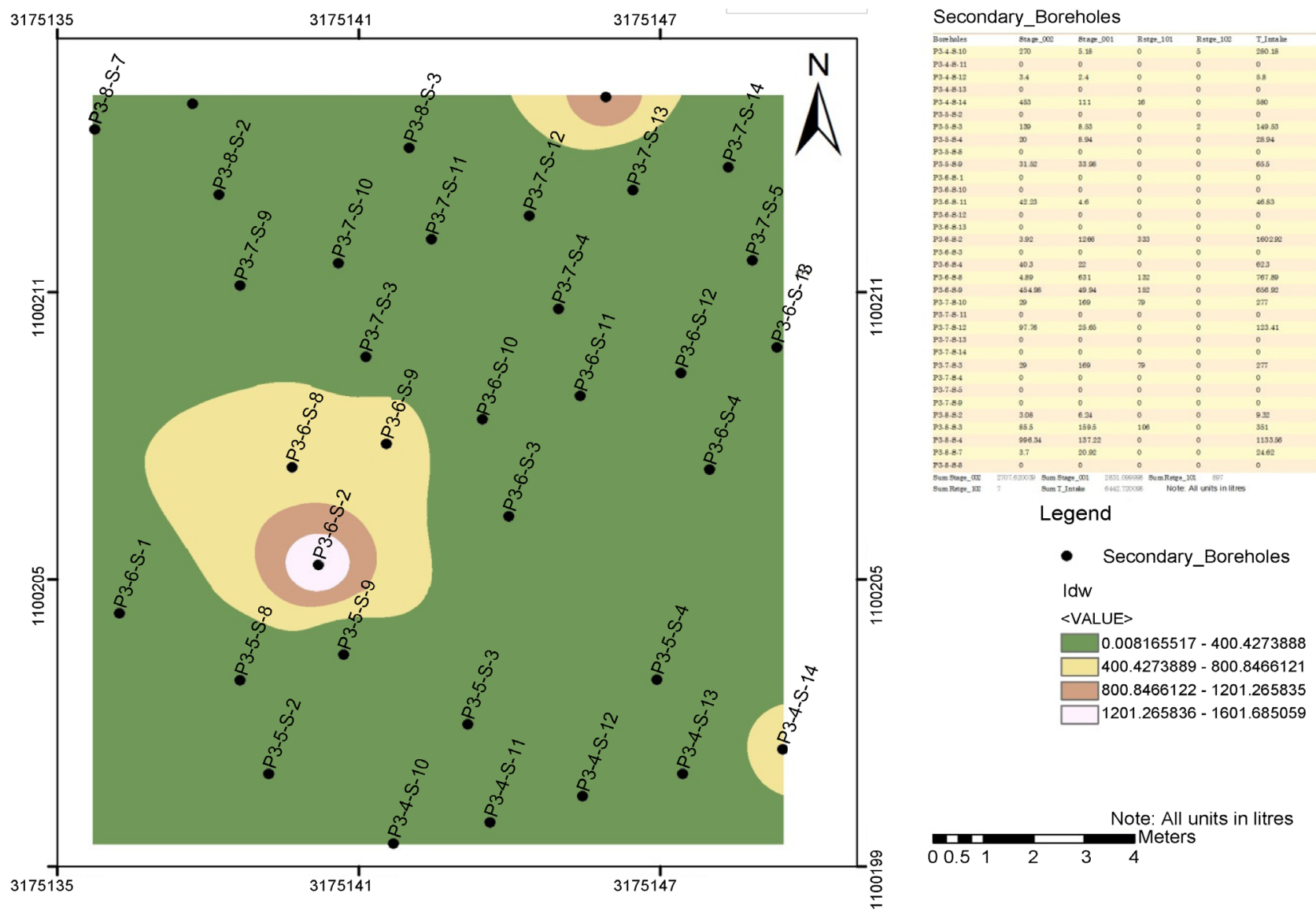

Figure 8. Cluster map of secondary boreholes showing areas of high grout takes. 


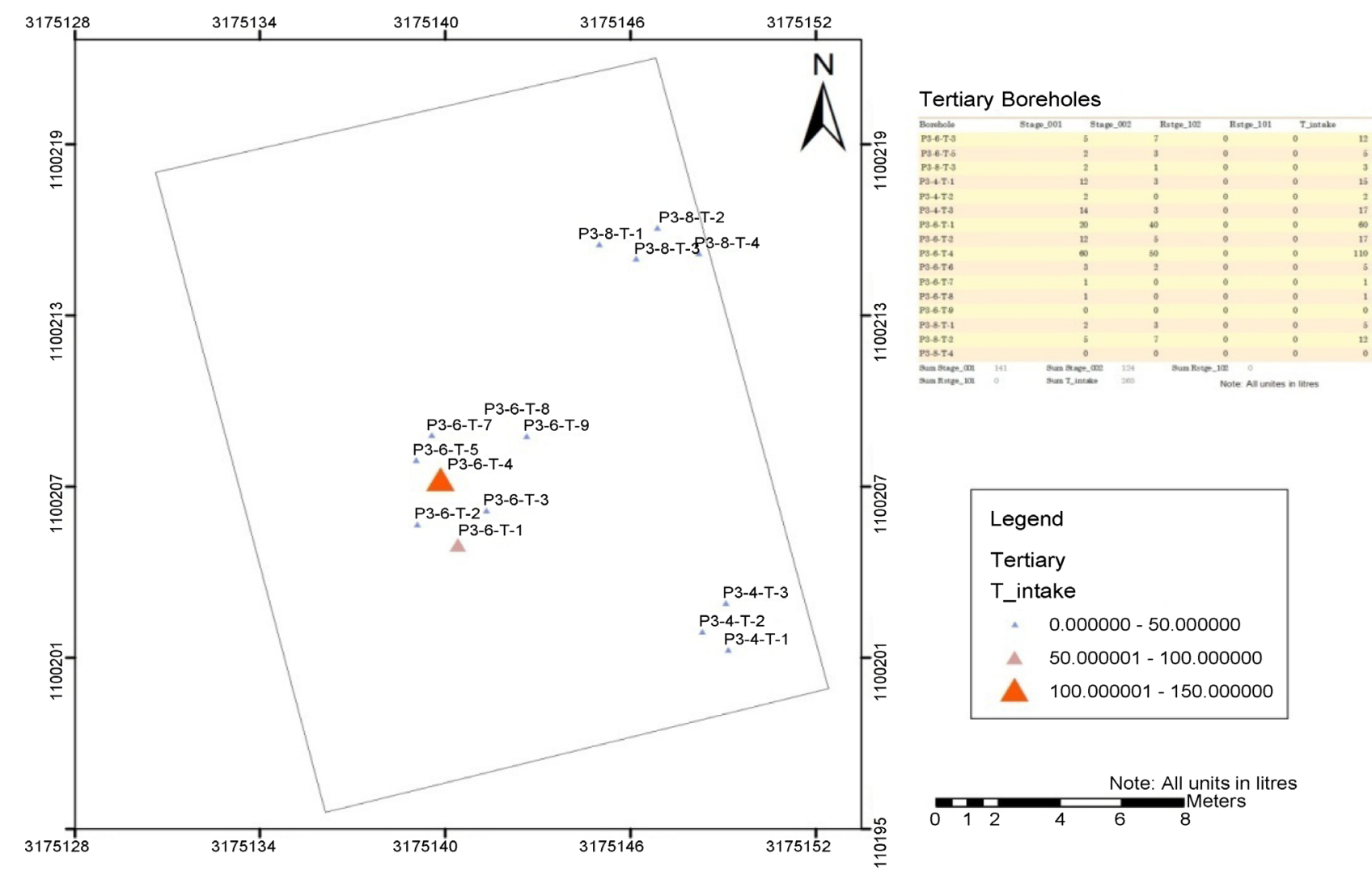

Figure 9. Tertiary boreholes location map (takes are based on color distribution of high, medium, and low).

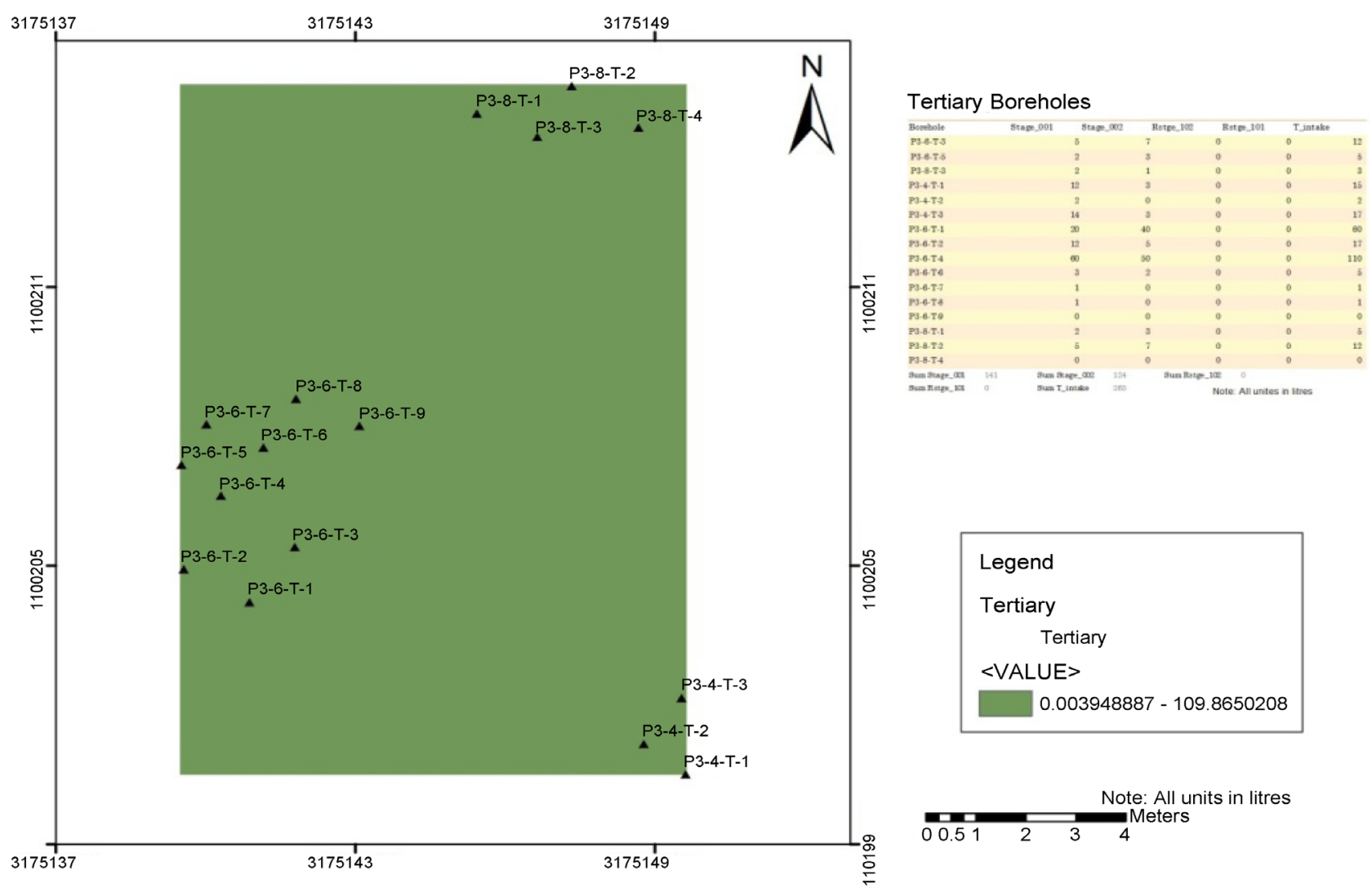

Figure 10. Cluster map of tertiary boreholes showing (areas with "NO” high grout takes). 
boreholes of the study area through GIS, it can be concluded that the GIN method through a GIS application is better than any observational method with regards to Consolidation Grouting of Rock Masses. The key benefit of utilizing GIS application for GIN grouting is to avoid the unnecessary drilling and grouting, which can lead to saving time, cost and provides quick results. To complete the drilling and grouting for Omega thrust block for penstocks, 3 weeks time frame was given, but with the help of innovative ArcGIS, it was possible to complete these operations within 1.5 weeks and without compromising on the quality of the work. The simple ArcGIS application is helpful for the project managers, engineers and geologists to complete the drilling and grouting operations before the given deadline.

\section{Acknowledgements}

We would like to sincerely acknowledge Prof. Dr. Sajid Rashid Ahmad for his guidance, and reviewing this paper.

\section{References}

[1] Ladiges, S., Willey, J., Norbert, M. and Barclay, A. (2010) Case Studies of Foundation Grouting Using the GIN Method at the Enlarged Cotter Dam. Vol. 39, GHD Pty Ltd for the Bulk Water Alliance, 1-18, 39.

[2] Hoek, E. (1994) Strength of Rock and Rock Masses. ISRM News Journal, 2, 4-16.

[3] Juge, B.L. (2012) Elastic Properties of Jet-Grouted Ground and Applications. Master's Thesis, Department of Civil Engineering, Texas A\&M University, 1-112.

[4] Dickinson, R.M. (1988) Review of Consolidation Grouting of Rock Masses and Methods for Evaluation. Vol. 4, Tech. No. AD A198 209, Department of the Army, US Army Corp of Engineers, Vicksburg, MS, REMR-GT-8, 1-86. http://www.dtic.mil/dtic/tr/fulltext/u2/a198209.pdf

[5] Lombardi, G. (1993) Grouting of Rock Masses. Rep. No. 102.1-R-147A, 01-42.

[6] Lombardi, G. (1996) Selecting the Grouting Intensity. The International Journal on Hydropower \& Dams, 3, 62-66.

[7] Ewert, F.K. (1997) GIN Principle Revisited. International Power and Dam Construction, Tunneling \& Rock Mechanics, 33-36.

https://www.lombardi.ch/it-it/SiteAssets/Publications/1091/Pubb-0270-E-GIN\%20 Principle\%20revisited.pdf

[8] Lombardi, G. and Deere, D. (1993) Grouting Design and Control Using the GIN Principle. International Water Power \& Dam Construction, 46, 15-22.

[9] Quittmeyer, R.L.R., Farah, A. and Jacob, K. (1979) The Seismicity of Pakistan and Its Relation to Surface Faults. Geodynamics of Pakistan, Geological Survey of Pakistan, 271-284.

[10] MonaLisa, Khwaja, A.A. and Jan, M.Q. (2007) Seismic Hazard Assessment of the NW Himalayan Fold-and-Thrust Belt, Pakistan, Using Probabilistic Approach. Journal of Earthquake Engineering, 11, 257-301. https://doi.org/10.1080/13632460601031243

[11] Babar, A. (2014) Preliminary Study of Reservoir Triggered Seismicity in the Vicinity of Tarbela Dam. Pakistan Journal of Meteorology, 11, 11-29.

[12] Mahdi, S.K. (1988) Tarbela Reservoir A Question of Induced Seismicity. Interna- 
tional Conference on Case Histories in Geotechnical Engineering, 48. http://scholarsmine.mst.edu/icchge/2icchge/2icchge-session3/48

[13] Hussain, A., Pogue, K., Khan, S.R. and Ahmad, I. (1991) Paleozoic Stratigraphy of the Peshawar Basin, Pakistan. Geological Bulletin, University of Peshawar, 24, 8597. http://nceg.uop.edu.pk/GeologicalBulletin/Vol-24-1991/Vol-24-1991-Paper7.pdf

[14] Khan, S.R., Khan, M.A., Nawaz, R. and Karim, T. (1990) Stratigraphic Control for the Age of Peshawar-Plain Magmatism, Northern Pakistan. Geological Bulletin, University of Peshawar, 23, 253-263. http://nceg.uop.edu.pk/GeologicalBulletin/Vol-23-1990/Vol-23-1990-Paper16.pdf

[15] Calkins, J.A., Offield, T., Abdullah, S. and Ali, S. (1975) Geology of the Southern Himalaya in Hazara, Pakistan, and Adjacent Areas. Geological Survey Professional Paper, 716c, 1-29. http://pubs.usgs.gov/pp/0716c/report.pdf

[16] Jan, M.Q., Khan, A.M. and Tahirkheli, T. (1981) The Geology and Petrography of Tarbela Alkaline Complex. Geological Bulletin, University of Peshawar, 14, 1-28.

[17] Kempe, D. and Jan, M. (1970) An Alkaline Igneous Province in the North-West Frontier Province, West Pakistan. Geological Magazine, 107, 395-398. https://doi.org/10.1017/S0016756800056260

[18] Kempe, D.R. (1973) The Petrology of the Warsak Alkaline Granites, Pakistan, and Their Relationship to Other Alkaline Rocks of the Region. Geological Magazine, 110, 385-404. https://doi.org/10.1017/S0016756800036189

Submit or recommend next manuscript to OALib Journal and we will provide best service for you:

- Publication frequency: Monthly

- 9 subject areas of science, technology and medicine

- Fair and rigorous peer-review system

- Fast publication process

- Article promotion in various social networking sites (LinkedIn, Facebook, Twitter, etc.)

- Maximum dissemination of your research work

Submit Your Paper Online: Click Here to Submit

Or Contact service@oalib.com 